Int. J. Electrochem. Sci., 15 (2020) $6561-6571$

International Journal of

ELECTROCHEMICAL

SCIENCE

WWW.electrochemsci.org

\title{
Prediction of the Elemental Content of Thin Films Electrodeposited from a Multi-component Solution: Co-Ni-Fe- Mn Thin Film as an Example of Multi-element Electrodeposits
}

\author{
M. Saitou \\ University of the Ryukyus, Department of Mechanical Systems Engineering, 1 Senbaru Nishihara-cho \\ Okinawa, 903-0213, Japan. \\ E-mail: saitou@tec.u-ryukyu.ac.jp
}

doi: $10.20964 / 2020.07 .23$

Received: 8 March 2020 / Accepted: 17 April 2020 / Published: 10 June 2020

The elemental content of $\mathrm{Co}-\mathrm{Ni}-\mathrm{Fe}-\mathrm{Mn}$ thin films electrodeposited by a rectangular pulse voltage were investigated using energy dispersive X-ray microscopy (EDX). The EDX analyses revealed that the behaviors of the mean elemental content $M_{i}$, where $i$ denotes an element of the Co-Ni-Fe-Mn thin films, were divided into three groups by the potential barrier $V_{b i}$ and cathode potential $V_{c}$ : (a) for $V_{c}>V_{b i}$, the values of $M_{i}$ were consistent with the activity $S_{i}$ of element $i$ in the solution, (b) for $V_{c}=V_{b i}$, the oscillation of the element- $i$ content occurred at specific frequencies of the rectangular pulse voltage, and (c) for $V_{c}<V_{b i}, M_{i}$ were determined by $S_{i} J_{i}$ where $J_{i}$ denotes the current in the Fowler-Nordheim equation that represents the emission of electrons from the Fermi level to the energy level of $i$-ions on the electric double layer. This study demonstrated that the elemental contents of multi-element electrodeposits can be predicted using $V_{b i}$ and $V_{c}$.

Keywords: Multi-component electrodeposit; Potential barrier; Cathode potential; Fowler-Nordheim equation;

\section{$\underline{\text { FULL TEXT }}$}

(C) 2020 The Authors. Published by ESG (www.electrochemsci.org). This article is an open access article distributed under the terms and conditions of the Creative Commons Attribution license (http://creativecommons.org/licenses/by/4.0/). 